\title{
Development, evaluation and characteristic of economically valuable traits in new sterile line of tomato for producing hybrids in the South of Russia
}

\author{
Irina Kozlova and Lyubov Esaulova* \\ Federal Scientific Rice Centre, Krasnodar, Russia
}

\begin{abstract}
To meet the needs of the population and commodity producers in southern Russia for tomato fruits, it is necessary to develop hybrids of various purposes, taking into account their increased adaptability to abiotic environmental factors that meet modern production technologies and market requirements, as well as combine high economically valuable traits and an acceptable price for seeds. The use of lines with a sterility trait may reduce labor costs for the production of hybrids and improve their quality. The purpose of these studies was to develop sterile lines of tomato for open ground for various purposes (fresh consumption and processing) and to obtain high-yielding hybrids on their basis. As a result of the research carried out, promising functionally sterile lines of tomato with a number of economically valuable traits have been developed, including large fruit size, productivity, lack of stalk articulation, biochemical parameters and commercial attractiveness of fruits. According to the length of the growing season, all inbred lines were divided into 3 groups: mid-early, mid-season, and mid-late. Further involvement of new sterile lines in the hybridization process as parent components in development of heterotic tomato hybrids resistant to abiotic environmental factors will make it possible to develop hybrids of various purposes for growing in open ground in the soil and climatic conditions of southern Russia.
\end{abstract}

\section{Introduction}

Vegetable growing is one of the most important and promising industries in the Russian Federation. Providing the population of Russia with high-quality food products throughout the year is an important task of the Government, which is intended to be solved by the "State Program for the Development of Agriculture of the Russian Federation", calculated until 2025.

Currently, about 640 thousand hectares of sown areas in the country are occupied by vegetable crops. Every year, $80 \%$ of the sown area in commercial vegetable growing and about $65 \%$ in PSP (personal subsidiary plots) is sown with imported varieties and hybrids. These figures indicate the critical dependence of domestic vegetable growing on imported

\footnotetext{
${ }^{*}$ Corresponding author: 1.esaulova@mail.ru
} 
seeds. In the event of the termination of the seed supply of foreign varieties and hybrids, the required volumes cannot be compensated for by domestic breeding developments.

The Lycopersicon esculentum Miller tomato $(2 n=2 x=24)$ is one of the most important nightshade vegetables grown worldwide. It is native to South America and Mexico. It is an important source of minerals, vitamins and acids for health [1]. According to the Food and Agriculture Organization of the United Nations (FAOSTAT, 2019), tomato production in 2019 exceeded 182 million tones and is widespread worldwide.

According to a number of authors, 0,58 thousand hectares are occupied by tomatoes in Krasnodar region, and their production volumes satisfy consumer demand by no more than half [2]. One of the reasons for this is the lack of domestic varieties that meet the requirements of commercial production and processing. Meeting the demand of the domestic market for seeds of vegetables and melons by 2025 at the level of $80 \%$ implies the development of competitive varieties and hybrids that are in demand in personal subsidiary plots and in production. At the same time, an important task of breeding is to develop varieties and hybrids with a stable realization of potential opportunities, with a high level of plasticity, resistance to unfavorable and stressful environmental factors, resistant to diseases and viruses.

The introduction of heterotic tomato hybrids into production is a way to improve the commercial quality of products, their ripeness and increase yields. In the domestic commercial production, $\mathrm{F}_{1}$ hybrids occupy an insignificant part. Since their seed production requires a lot of manual labor for isolation, castration and marking of flowers. In this regard, the prime cost of hybrid seeds is very high [3]. The use of functional male sterility may reduce the cost of hybrid seeds. The organization of mass seed production of hybrids developed on the basis of FMS lines in the south of Russia makes it possible to produce cheaper high-quality hybrid seeds for open ground, which is an important prerequisite for import substitution.

Development of new tomato varieties and heterotic $F_{1}$ hybrids for open ground for various purposes (fresh consumption, whole-fruit canning, tomato products production, etc.), taking into account their increased adaptability to abiotic environmental factors that meet modern production technologies and consumer requirements, as well as combining high economically valuable traits and an acceptable price for seeds is an urgent task for breeders at the present stage. High temperatures significantly affect seeds, pollen vitality and root growth [4]. The tomato as both a fresh consumption and industrial product is one of the most profitable vegetables and has a large cultivation area in the world. Parallel to intense production activities, Tomato Spotted Wilt Virus (TSWV), like viral diseases, results in significant economic losses every year [5]. Adaptableness to environmental changes generally derives from a large set of genetic traits affecting physio-morphological, biochemical and agronomic parameters. Therefore, the identification of genotypes with higher yield and good quality parameters at high temperatures is becoming increasingly necessary for future breeding programs [6].

Currently, the main emphasis in breeding work to expand the assortment of tomatoes is on the development of $F_{1}$ hybrids based on maternal forms with functional male sterility (FMS). Work is underway to develop new maternal lines of tomato with the FMS trait, which have large fruits; fruits of raspberry-red color; fruits without stalk articulation, with high organoleptic and biochemical characteristics, adapted to the soil and climatic conditions of the south of Russia, possessing resistance to major diseases and viruses.

The aim of the research is to develop valuable tomato lines for open ground for various purposes (fresh consumption, whole-fruit preservation, production of tomato products, etc.) and, on their basis, to obtain high-yielding hybrids. To develop the elements of seed production of these hybrids in a film greenhouse. 


\section{Materials and methods}

The studies were carried out in 2015 - 2020 in breeding film greenhouse and field conditions on the territory of the experimental plot of Federal State Budgetary Scientific Institution "Federal Scientific Rice Centre" in the central soil and climatic zone of Krasnodar region.

The soil of the experimental plot is represented by Western Ciscaucasian superpowerful low-humus leached chernozems. Their mechanical composition is predominantly clayey. Strong leaching, heavy mechanical composition of soils are the reason for their easy swimming after rains and the formation of a dense crust on the surface. The climate is temperate continental with mild winters, long growing seasons and moderate rainfall. Along with the positive aspects of the climate, there are some negative points: hot summers, high evaporation, the presence of dry winds. In general, the climatic conditions are quite favorable for the tomato cultivation.

During the years of testing, in the summer months, there were long dry periods with high air temperatures (up to 40 degrees or more), which adversely affected flowering and fruit setting. Sunburns of fruits were observed in samples with slightly leafy shrubs. These unfavorable abiotic environmental factors made it possible to select tomato biotypes with increased resistance to high temperatures and changes in air humidity.

The object of research were sterile tomato lines, new $F_{1}$ hybrids based on FMS, collection, breeding material, varieties and hybrids bred in FSBSI Federal Scientific Rice Centre.

In the breeding work, the methods of classical breeding were used [7, 8, 9]. Sterile forms provided by LLC "Breeding station named after N.N. Timofeev "of the Moscow Agricultural Academy, were used in the breeding process as donors for introducing alleles of the genes of functional male sterility ps-2 (positional sterility - 2) into new parental forms by the method of 3-4 times backcrossing. As donors of the economic traits, we used the paternal breeding lines bred in FSBSI Federal Scientific Rice Centre. The types of crosses used in the work: analyzing, saturating, top-crosses. To accelerate the process of developing new sterile tomato lines in winter, artificial climate chambers were used. Backcrosses to develop new sterile lines, selection of sterile plants from the splitting hybrid generation were carried out in a hybridization nursery, located in a film spring unheated greenhouse with side and ridge ventilation.

Agrotechnical measures on crops were carried out in accordance with the recommendations for growing tomato [10]. Watering - drip irrigation. Statistical processing of the experimental results - according to B.A. Dospekhov [11] and A.Kh. Sheudzhen [12]. In the course of the work, samples in the initial material and biotypes were selected to include this material in the program of further breeding work.

\section{Results}

Since 2015, work has been carried out in the breeding nursery to develop and study new sterile tomato lines for open ground. Based on four initial forms with functional male sterility, semi-determinant type of growth and low-growing donors of traits such as "large fruit mass", "high palatability", "aroma", "high dry matter content", "no articulation of the stalk", "density of pulp and skin ", $70 \mathrm{~F}_{1}$ hybrids were developed, possessing a number of useful economically valuable traits. Of these, 15 most productive combinations were selected by the method of individual selection. From the splitting populations of $\mathrm{F}_{2}$ and $\mathrm{F}_{3}$ hybrids, new interesting forms were obtained in color and shape of the fruit, for various purposes (fresh consumption, whole-fruit canning, production of tomato products, etc.), possessing the FMS trait. As a result, a number of lines were obtained, which, starting from 
2019, were evaluated according to phenotypic and biometric indicators. The duration of the phenological phases of the isolated samples is shown in Table 1. From the table it can be seen that the shortest duration of the interfacial period "germination - beginning of flowering" (42 days) was recorded in samples $7 \mathrm{f}$ and $7 \mathrm{f}-19$. Later flowering was observed in biotypes 2f2, 1f, 14-1 and 14-3 (48 - 49 days). A short interfacial period "floweringripening" 45 days was shown by sample w-11/1, long (59 days) $-2 \mathrm{ph} 2$ and $1 \mathrm{ph}$. The start of ripening 90 days after the emergence of seedlings was recorded in lines $7 \mathrm{f}$ and $\mathrm{w}-11 / 1$, the latest - in line 1f - 107 days and 2 f2 - 108 days.

Table 1. The duration of the periods of passing phenological phases in tomato biotypes with the FMS trait

\begin{tabular}{|c|c|c|c|c|c|}
\hline \multirow{2}{*}{$\begin{array}{c}\text { Sample } \\
\text { name }\end{array}$} & \multirow{2}{*}{$\begin{array}{c}\text { Date of } \\
\text { emergence }\end{array}$} & \multicolumn{4}{|c|}{ Number of days from mass seedlings till } \\
\cline { 3 - 6 } & of seedlings & $\begin{array}{c}\text { transplanting in film } \\
\text { greenhouse }\end{array}$ & $\begin{array}{c}\text { start of } \\
\text { flowering }\end{array}$ & $\begin{array}{c}\text { mass } \\
\text { flowering }\end{array}$ & $\begin{array}{c}\text { start of } \\
\text { ripening }\end{array}$ \\
\hline 7f & 02.03 & 30 & 42 & 49 & 90 \\
\hline sh-11/1 & 02.03 & 30 & 45 & 50 & 90 \\
\hline sh-23 & 02.03 & 30 & 45 & 50 & 92 \\
\hline 2f2 & 02.03 & 30 & 49 & 57 & 108 \\
\hline 1f & 02.03 & 30 & 48 & 57 & 107 \\
\hline 3f & 02.03 & 30 & 45 & 51 & 95 \\
\hline $14-1$ & 02.03 & 30 & 48 & 56 & 100 \\
\hline $14-3$ & 02.03 & 30 & 48 & 56 & 100 \\
\hline $17-1$ & 02.03 & 30 & 45 & 51 & 95 \\
\hline $7 f-19$ & 02.03 & 30 & 42 & 50 & 92 \\
\hline
\end{tabular}

Analyzing the data in Table 2 by duration of the growing season, all sterile biotypes were divided into 3 groups: mid-early (1), mid-season (2) and mid-late (3). The mid-early group included samples of the salad direction $7 f, w-11 / 1, w-23$ and $7 f-19$. The line is characterized by a determinant type of growth, shortened internodes, large flat-round and round fruits with weak ribbing, bright color (see Table 3). The mid-season group included lines of the universal direction 17-1 and 14-3, with a fruit weight of 80-120 grams, suitable both for fresh consumption and for processing into tomato products, as well as lines for developing hybrids intended for processing (3f and 14-1). These lines are characterized by the absence of stalk articulation, which indirectly indicates the possibility of using machine harvesting, high density of pulp and skin, which are an essential requirement for professional hybrids intended for transportation and processing into tomato products. The middle late group included the lines of the universal direction ( $1 \mathrm{f}$ and $2 \mathrm{f} 2$ ).

Table 2. Duration of growing season of sterile tomato biotypes

\begin{tabular}{|c|c|c|}
\hline Sample & Group & Number of days from seedlings till start of fruit ripening \\
\hline $7 \mathrm{f}$ & \multirow{4}{*}{1} & \multirow{4}{*}{$90-92$} \\
\hline sh-11/1 & & \\
\hline sh-23 & & \\
\hline $7 f-19$ & & \\
\hline $17-1$ & \multirow{4}{*}{2} & \multirow{4}{*}{$95-100$} \\
\hline $3 \mathrm{f}$ & & \\
\hline $14-1$ & & \\
\hline $14-3$ & & \\
\hline $1 \mathrm{f}$ & \multirow{2}{*}{3} & \multirow{2}{*}{$107-108$} \\
\hline $2 \mathrm{f} 2$ & & \\
\hline
\end{tabular}




\section{Discussion}

The primary selection of lines with economic traits of interest in combination with the trait of sterility was carried out according to the color, weight, shape and commercial qualities of the fruit (Table 3). The lines developed in the department of vegetable and potato growing of FSBSI Federal Scientific Rice Centre are widely used in breeding of open field hybrids. They have a determinant type of bush, good foliage and are resistant to abiotic environmental factors.

Table 3. Characteristic of selected sterile tomato samples

\begin{tabular}{|l|l|l|l|l|l|}
\hline Sample & \multicolumn{2}{|l|}{ Characteristic of fruits } & \multirow{2}{*}{ Articulation } \\
\cline { 2 - 5 } & $\begin{array}{l}\text { Mass variation, } \\
\mathrm{g}\end{array}$ & Shape & $\begin{array}{l}\text { Number of } \\
\text { dissepiments }\end{array}$ & Color & \\
\hline $7 \mathrm{f}$ & $200-250$ & flatly-roundish & $5-6$ & red & present \\
\hline sh-11/1 & $150-180$ & roundish & $4-5$ & pink & absent \\
\hline sh-23 & $130-150$ & roundish & $4-5$ & yellow & present \\
\hline $7 \mathrm{f}-19$ & $280-300$ & flatly-roundish & $6-10$ & red & present \\
\hline $17-1$ & $80-110$ & roundish & $2-3$ & red & present \\
\hline $3 \phi$ & $50-60$ & cylindric & $2-3$ & red & absent \\
\hline $14-1$ & $50-60$ & cubiform & $2-3$ & red & absent \\
\hline $14-3$ & $80-120$ & roundish & $3-4$ & red & present \\
\hline $1 \phi$ & $100-120$ & roundish & $3-4$ & raspberry red & absent \\
\hline $2 \phi 2$ & $90-100$ & cylindric & $3-4$ & red & absent \\
\hline
\end{tabular}

Starting with $\mathrm{F}_{4}$, breeding work to develop new sterile lines was carried out with the progeny of sterile $7 f$ and $1 f$ hybrid plants. Economically valuable traits were consolidated by inbreeding. New sterile line $7 \mathrm{f}$ mid-early ripening, salad direction. It has a simple brush, in which 3-4 flat-roundish red fruits weighing 200-250 grams, of harmonious taste are formed, a stem with an articulation. Determinate bush, medium-sized, well-leafy, completely protecting the fruit from sunburn.

Maternal line $1 \mathrm{f}$ is of the mid-late ripening, universal direction. It has a medium-sized determinant, well-leafy bush. Fruits are even in size, round, smooth, shiny, raspberry red color, with 4 - 5 dissepiments, average weight 100-120 grams, with dense skin. For a long time they can be stored on the bush without losing marketability. Peduncle has no articulation. When developing tomato lines, much attention is paid to the taste of fruits, both lines and hybrids developed on their basis. Tomatoes are consumed in very large amounts worldwide, but to date, few reports on the quantitative trait loci (QTLs) for the sugar content in tomato fruits have been published [13]. YaoTang et al. determined that the inheritance of the soluble sugar content in tomato fruits follows a negative dominance model with a predominantly polygenic effect.

In our research, regular tastings are carried out, and the search for donors of the "harmonious taste" trait is underway. Since this trait is determined by the combination of sugar content and acidity in fruits, the laboratory of agrochemistry conducts biochemical analyzes to determine dry matter, ascorbic acid, total sugar and acidity in fruits of lines and hybrids. The results of biochemical analysis (table. 4), made it possible to identify lines with high levels of vitamin $\mathrm{C}$. These are lines sh- 23 and $2 \mathrm{f} 2$ (the content of ascorbic acid is in the range of $35,76-37,36 \mathrm{mg} \%$ ). The dry matter content in tomato fruits ranged from 4,55 to $5,93 \%$. The greatest accumulation of dry matter $(5,66-5,93 \%)$ was observed in the lines of the canning direction (14-1 and 3f), in the lines of the salad direction (7f, w-11/1, w-23.7f-19) - within 4,55-4,84\%. About half of the dry matter is sugars. The sugar content in tomato fruits was in the range of $1,93-2,64 \%$, the highest indices were for the 
lines $7 f-19$ and $14-3$ with a content of 2,63-2,64\%. The sugar-acid coefficient of new sterile lines varied within $5,59-8,17$.

Table 4. Results of biochemical analysis of fruits of sterile tomato samples, 2020

\begin{tabular}{|c|c|c|c|c|c|c|}
\hline $\begin{array}{c}\text { Plot } \\
\text { № }\end{array}$ & $\begin{array}{c}\text { Hybrid } \\
\text { name }\end{array}$ & $\begin{array}{c}\text { Dry matter } \\
\text { content, } \%\end{array}$ & $\begin{array}{c}\text { Total } \\
\text { sugar } \\
\text { content, } \%\end{array}$ & $\begin{array}{c}\text { Total acidity } \\
\%\end{array}$ & $\begin{array}{c}\text { Ascorbic acid } \\
\text { content, mg/\% }\end{array}$ & $\begin{array}{c}\text { Sugar- } \\
\text { acid } \\
\text { index }\end{array}$ \\
\hline 48 & $7 \mathrm{f}$ & 4,68 & 2,24 & 0,27 & 29,11 & 8,29 \\
\hline 49 & sh-11/1 & 4,55 & 2,37 & 0,34 & 24,45 & 6,95 \\
\hline 51 & sh-23 & 4,84 & 2,21 & 0,28 & 37,36 & 7,84 \\
\hline 54 & $7 \mathrm{f}-19$ & 4,73 & 2,63 & 0,32 & 26,2 & 8,17 \\
\hline 58 & $17-1$ & 5,11 & 2,31 & 0,34 & 25,03 & 6,79 \\
\hline 59 & 3f & 5,93 & 2,41 & 0,33 & 30,27 & 7,03 \\
\hline 60 & $14-1$ & 5,66 & 2,48 & 0,35 & 31,43 & 7,08 \\
\hline 61 & $14-3$ & 5,16 & 2,64 & 0,42 & 30,27 & 6,29 \\
\hline 68 & 1f & 5,12 & 1,93 & 0,3 & 29,11 & 6,43 \\
\hline 69 & 2f2 & 5,51 & 2,18 & 0,39 & 35,76 & 5,59 \\
\hline
\end{tabular}

To study the combining ability based on yield, the new lines were included in the topcross crosses with paternal forms with a high total combining ability (TCA).

In 2021, the $F_{1}$ tomato hybrid of salad direction - Zarnitsa-75 passed the State variety test and was included in the State Register of Breeding Achievements, allowed for use in the Russian Federation (Fig. 1).

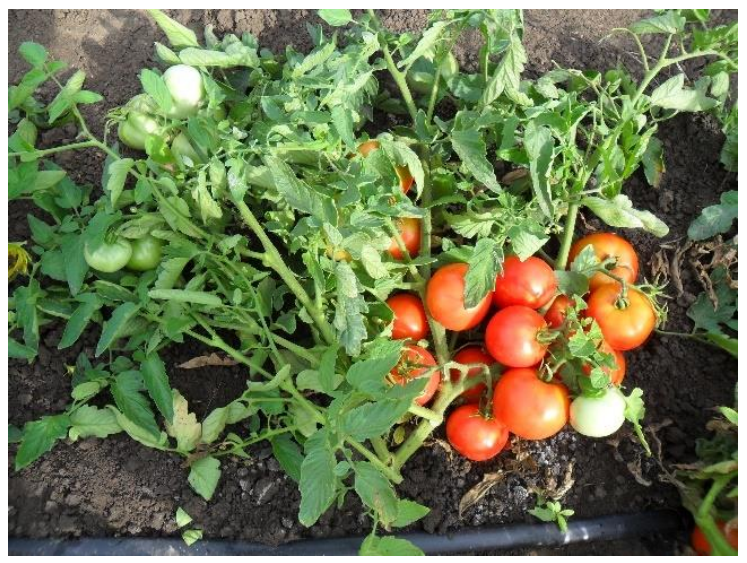

Fig. 1. $F_{1}$ tomato hybrid Zarnitsa

The hybrid was first obtained in 2016 by the method of controlled crossing of inbred breeding lines with a trait of functional male sterility, bred at LLC "Breeding Station named after N.N. Timofeev", Moscow Agricultural Academy and the department of vegetable and potato growing of FSBSI Federal Scientific Rice Centre, in the previous years of research. The hybrid is intended for cultivation in the open ground of the soil and climatic conditions of the south of Russia. The average ripening period, from seedlings to the start of ripening 97 - 113 days, a determinant bush, medium-sized, well-leafy, completely protecting the fruit from sunburn. Fruits are flatly-roundish in shape, with a slight ribbing at the stalk, dense pulp and skin, red in color, and have good taste. For a long time they can be stored on the bush without losing marketability. The peduncle is articulated. In a bunch there are 5-6 fruits with an average weight of 130-160 g. The yield of marketable fruits when grown on 
irrigation is 118 - $119 \mathrm{t} / \mathrm{ha}$. For two years of testing (2018-2019) the $\mathrm{F}_{1}$ hybrid Zarnitsa-75 exceeded the standard $\mathrm{F}_{1}$ Module in yield by $7.8-9.2 \mathrm{t} / \mathrm{ha}$.

\section{Conclusions}

As a result of the research, promising new functionally sterile lines of tomato were identified, differing in duration of growing season, weight, color, shape of the fruit, biochemical indicators, possessing a number of economically valuable traits. New breeding samples have determinant well-leafy bushes that protect the fruits from sunburn. Their further involvement in the hybridization process as parent components in the development of heterotic tomato hybrids resistant to abiotic environmental factors will make it possible to develop hybrids of various directions for growing in the open ground of the soil and climatic conditions of southern Russia.

\section{References}

1. G. Kalloo. Genetic Improvement of Vegetable Crops, 1993, Pages 645-666. https://doi.org/10.1016/B978-0-08-040826-2.50049-7

2. Open ground tomatoes: areas and harvests in Russia in 2001-2019. [Electronic resource] - Access mode: https: // agrovesti.net / lib/industries / vegetables /pomidory-otkrytogogrunta-ploshchadi-i-sbory-v-rossii-v-2001-2019-gg.html (Date of application: 25.11.2020).

3. M.S. Bunin, G.F. Monakhos, V.I. Terekhova, Production of hybrid vegetable seeds: textbook /. - M.: Publishing house of the Russian State Agrarian University, Moscow Agricultural Academy named after Timiryazev, 2011, 182 p.

4. Muhammed Alsamir, Tariq Mahmood, Richard Trethowan, Nabil Ahmad. An overview of heat stress in tomato (Solanum lycopersicum L.), Saudi Journal of Biological Sciences. Volume 28, Issue 3, March 2021, Pages 1654-1663. https://doi.org/10.1016/j.sjbs.2020.11.088

5. Aylin Kabaş, Hakan Fidan et al. Identification of new sources of resistance to resistance-breaking isolates of tomato spotted wilt virus. Saudi Journal of Biological Sciences. Available online 21 February 2021. https://doi.org/10.1016/j.sjbs.2021.02.053

6. Amrutha Vijayakumar et al. High temperature induced changes in quality and yield parameters of tomato (Solanum lycopersicumL.) and similarity coefficients among genotypes using SSR markers. Heliyon. Volume 7, Issue 2, February 2021. https://doi.org/10.1016/j.heliyon.2021.e05988

7. Savchenko V.K. A method for assessing the combining ability of genetically diverse sets of parental forms, Methods of genetic-breeding and geneting experiments. Minsk, 1973, p. 48-77.

8. Guidelines for breeding tomato varieties and hybrids for open and protected ground. M., VNIISSOK, 1986, 64p.

9. Litvinov, S.S. Field experiment technique in vegetable growing, M.: Russian Agricultural Academy, 2011.- 648 p.

10. Grushanin A.I., Esaulova L.V., et al, Technology for growing tomatoes in the open ground in the Kuban. Recommendations, Krasnodar, 2016, 36p.

11. Dzyuba V.A. Multivariate experiments and methods of biometric analysis of experimental data. Guidelines, Krasnodar, 2007, 76 p. 
12. A.Kh. Sheudzhen, T.N. Bondareva, Methods of agrochemical research and statistical evaluation of their results, Maykop: JSC Polygraph-YUG, 2015, 664 p.

13. YaoTang et al. Genetic characteristics and QTL analysis of the soluble sugar content in ripe tomato fruits. Scientia Horticulturae. Volume 276, 27 January 2021, 109785. https://doi.org/10.1016/j.scienta.2020.109785

14. Jia Lu, Guangcheng Shao et al. Effects of water deficit combined with soil texture, soil bulk density and tomato variety on tomato fruit quality: A meta-analysis. Agricultural Water Management. Volume 243,1 January 2021, 106427. https://doi.org/10.1016/j.agwat.2020.106427 